\title{
Analysis of changes of relationship between water level and discharge and its causes at the tail of Fuhe River in recent $\mathbf{7 0}$ years
}

\author{
Hua $\mathrm{GE}^{1, *}$, Chunyan DENG ${ }^{1}$ \\ ${ }^{1}$ Changjiang River Scientific Research Institute, Wuhan, Hubei, 430010, China
}

\begin{abstract}
Based on the measured day-averaged water level and discharge data of the tail reach of Fuhe River, the changes of hydrological situation in recent 70 years was analysed in this paper. The results show that the relationship between the water level and discharge at the tail of Fuhe River has been greatly changed, and the water level at the same discharge was significantly reduced. These changed were not related to the runoff changes, but mainly affected by the changes of river bed and downstream boundary water level.
\end{abstract}

\section{Introduction}

Over the years, under the multiple effects of non-human and human factors, the hydrological situation of Poyang Lake region has been significantly changed [1-3]. It is obvious that that the relationship between water level and discharge in the tail areas of the five major in-lake river systems has also changed. Among them, Ganjiang River tail is especially concerned by many scholars for its important political and economic status [4-5]. Fuhe River Basin, located in the southeast of Jiangxi Province, is one of the five major rivers in Poyang Lake system. It passes through Jiaoshi barrage and Qinglan lake and flows into Poyang Lake in Sanyang. The tail of Fuhe River has a similar economic and social status to that of Ganjiang Rive. It is also an important habitat for migratory birds, zooplankton and aquatic plants. However, the change of its hydrological situation has not attracted enough attention. Based on the historical hydrological data of this area, this paper analyses the hydrological situation, as well as the internal mechanism driving its changes. The relevant research results can provide technical support for the development, utilization and protection of Fuhe River.

\section{Study area, data and method}

\subsection{Study area and data}

Fuhe River is one of the five main rivers in Poyang Lake system. The Fuhe River basin is located in the southeast of Jiangxi Province, spanning $115^{\circ} 30^{\prime}$ to $117^{\circ} 10^{\prime} \mathrm{E}$ and $26^{\circ} 30^{\prime}$ to $28^{\circ} 27^{\prime} \mathrm{N}$. The river runs from south to north with a total length of $349 \mathrm{~km}$ and a basin area of $17186 \mathrm{~km} 2$. The length from Heyuan to Nancheng is
$158 \mathrm{~km}$, called Xujiang River, which is the upper reach with a width of about $200-400 \mathrm{~m}$ and an average gradient of $3.4 \%$; the middle reaches from Nancheng to Fuzhou is $77.4 \mathrm{~km}$ in length, with a width of $400-600 \mathrm{~m}$ and an average gradient of $0.44 \%$; the Fuhe River flows into the downstream plain area after passing through Fuzhou City and flows into the downstream plain area, with a width of $400-1000 \mathrm{~m}$. Among this, Fuzhou to Lijiadu is about $42.6 \mathrm{~km}$ in length, with an average gradient of $0.26 \%$. Downstream Lijiadu to Sanyang, the study area in this paper, is $71 \mathrm{~km}$ long with an average slope of $0.15 \%$ o shown as Figure 1 .

In this section, there is a Lijiadu hydrological station, which controls the inflow of Fuhe River into the Poyang lake, and has the daily average water level and discharge observation data since 1956. There are another two water level observation stations, called as Wenzhen station and Sanyang station in the lower reaches of Lijiadu. Wenzhen station has continuous water level observation data since 1970s, and Sanyang station has continuous water level observation data since 1950s. The daily average water level and discharge data of the three hydrological stations constitute the database of this study.

\subsection{Method}

The change of hydrological situation is mainly reflected by the change of relationship curves between the water level $\mathrm{Z}$ and discharge Q. In this study, the relationship curve between water level and discharge is drawn by a standardized data series. The standardization method is as follows:

$$
\begin{gathered}
\mathrm{Q}_{s}=\left(Q_{i}-Q_{\min }\right) /\left(Q_{\max }-Q_{\min }\right) \\
Z_{s}=\left(Z_{i}-Q_{\min }\right) /\left(Z_{\max }-Z_{\text {min }}\right)
\end{gathered}
$$

Where $\mathrm{Qi}$ and $\mathrm{Zi}$ are the daily average flow discharge and water level, Qmin and Zmin are the minimum value

\footnotetext{
* Corresponding author: gh-102@126.com
} 
of flow and water level, and Qmin and Zmin are the maximum value. After the above-mentioned standardization process, the relationship between standardized water level and discharge of each year is plotted on the same map. The historical change of hydrological situation can be clearly reflected by the change of data distribution area in each year.

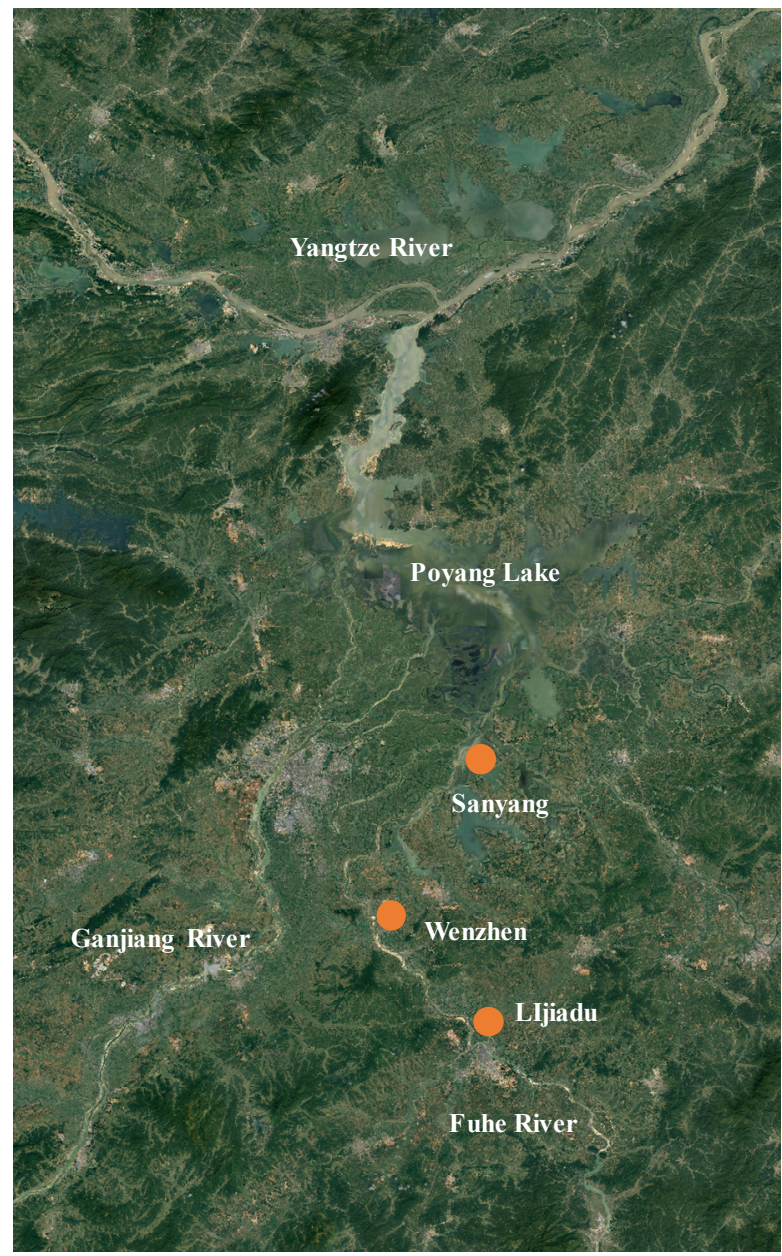

Fig. 1. Map of the study area.

The causes of the change are mainly analysed from three aspects: runoff, river bed evolution and down boundary water level conditions. The change of runoff is mainly reflected by the annual average runoff. The influence of river bed evolution and lower boundary water level conditions is mainly reflected in the water level correlation between upstream and downstream. Through the change of correlation relationship, we can distinguish the influence of river bed evolution and lower boundary water level conditions.

\section{Results}

\subsection{Change of $Q \sim Z$ relationship}

Figure 2 shows the variation of $\mathrm{Q} \sim \mathrm{Z}$ relationship at Lijiadu hydrological station over the 60 years. It can be clearly seen from the figure that the water level of Lijiadu hydrological station under the same discharge is in a continuous decline process, and the decline range is relatively large. From 1956 to 2019, the drawdown range of water level under different discharge is $1.9 \mathrm{~m}$ to $4.2 \mathrm{~m}$.

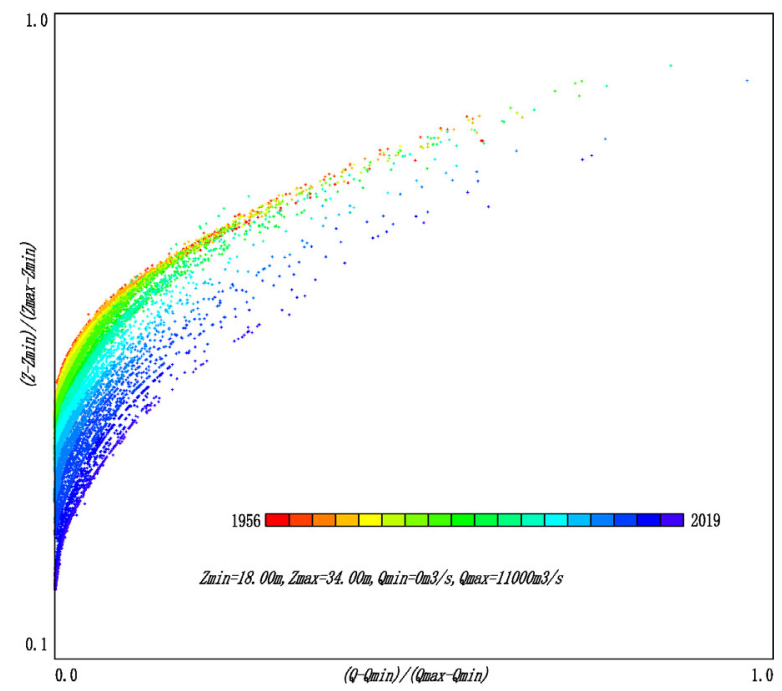

Fig. 2. Map of the changes of $Q \sim Z$ relationship.

Table 1 gives the water level drop of different discharge. It can be seen that the greater the discharge, the smaller the water level drop. For example, the water levels of $1000 \mathrm{~m} 3 / \mathrm{s}, 3000 \mathrm{~m} 3 / \mathrm{s}$ and $5000 \mathrm{~m} 3 / \mathrm{s}$ in 1956 are $27.7 \mathrm{~m}, 29.4 \mathrm{~m}$ and $30.0 \mathrm{~m}$ respectively. And in 2019 , the corresponding water levels are $24.5 \mathrm{~m}, 27 . \mathrm{m}$ and $28.7 \mathrm{~m}$, with the decrease range of $3.1 \mathrm{~m}, 2.4 \mathrm{~m}$ and $1.3 \mathrm{~m}$ respectively.

Table 1. Water level drop of different discharge.

\begin{tabular}{|c|c|c|c|}
\hline \multirow{2}{*}{$\begin{array}{l}\text { Discharge } \\
\qquad\left(\mathrm{m}^{3} / \mathrm{s}\right)\end{array}$} & \multicolumn{2}{|c|}{ Water Level (m) } & \multirow{2}{*}{$\begin{array}{l}\text { Water Level } \\
\text { drop }(\mathrm{m})\end{array}$} \\
\hline & 1956 & 2019 & \\
\hline 500 & 26.8 & 23.5 & -3.3 \\
\hline 1000 & 27.7 & 24.5 & -3.1 \\
\hline 1500 & 28.2 & 25.1 & -3.1 \\
\hline 2000 & 28.6 & 25.7 & -2.9 \\
\hline 2500 & 29.0 & 26.3 & -2.6 \\
\hline 3000 & 29.4 & 27.0 & -2.4 \\
\hline 3500 & 29.8 & 27.6 & -2.2 \\
\hline 4000 & 30.1 & 28.1 & -1.9 \\
\hline 4500 & 29.9 & 28.5 & -1.4 \\
\hline 5000 & 30.0 & 28.7 & -1.3 \\
\hline
\end{tabular}

Figure 3 gives an annual-averaged water level from 1960 to 2019. From the declining trend over the years, the rate of water level decline was small before 2000, but increased after that. 


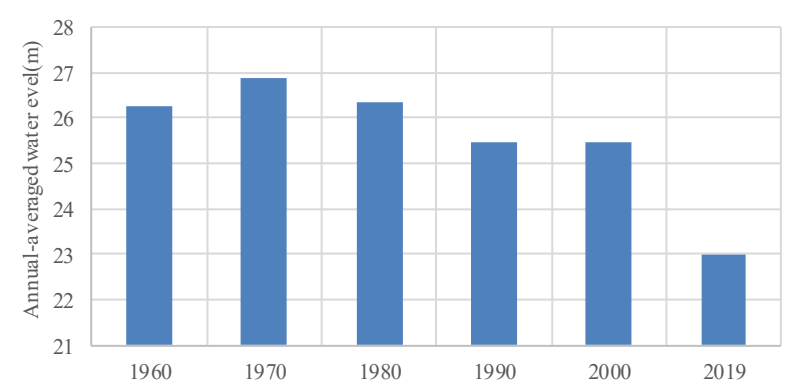

Fig. 3. Annual-averaged water level from 1960 to 2019.

\subsubsection{Influence of the runoff}

Runoff is the primary factor affecting the water level of the reach, and the change of runoff will deeply affect the water level. Figure 4 shows the annual average runoff of Lijiadu station over the years. It can be seen from the figure that the average annual runoff of Lijiadu has not changed significantly over the years. From the 10-year moving average line we can see, that it has even increased slightly in recent 10 years. Therefore, runoff is not the reason for the downward movement of Lijiadu stage's Q Z relationship.

\subsection{Reasons of the changes}

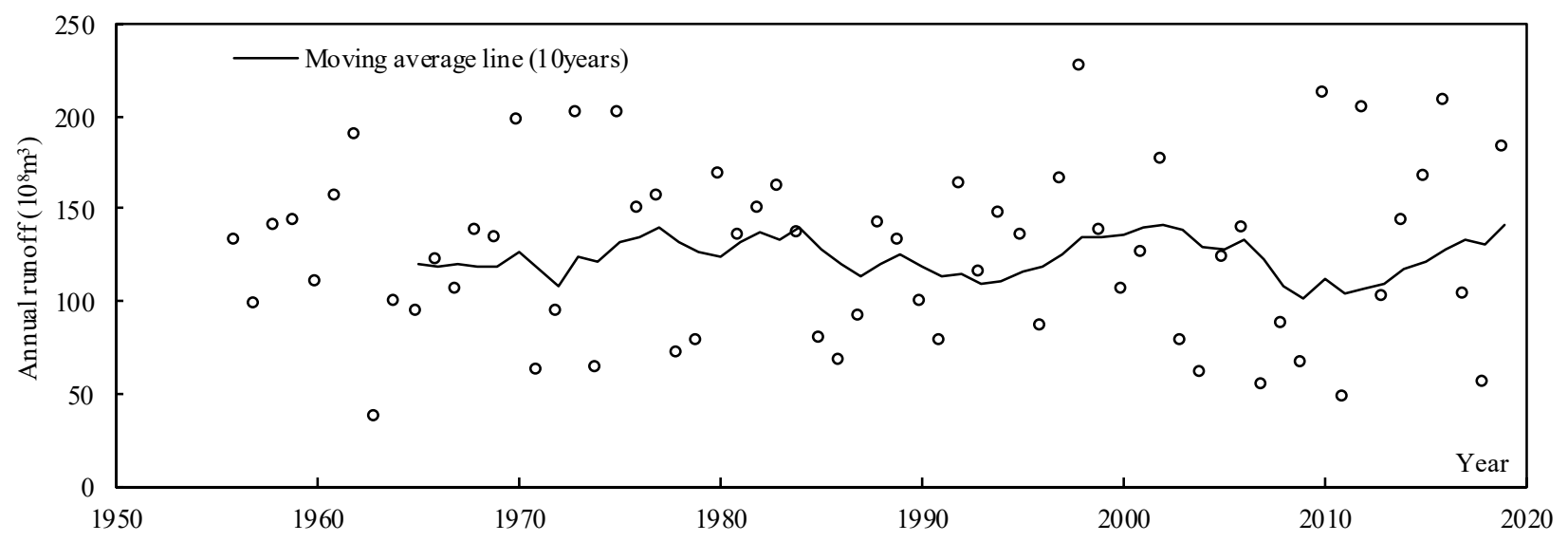

Fig. 4. Map of annual runoff of Lijiadu station.

\subsubsection{Influence of the river bed evolution and lower boundary water level conditions}

There are many aspects of river bed evolution, such as river bed degradation/erosion, regulation, and riverrelated projection. The influence of the above-mentioned changes on the water level in a reach is finally reflected in the water level correlation between the upstream and downstream of the reach. Figure $5 \sim$ Figure 6 show the variation of water level correlation ship of the upstream and downstream water level stations in the study reach. It can be seen from the figures that the overall change of water level correlation between Lijiadu station and Wenzhen station is relatively small. Among them, Lijiadu water level rose about $0.4 \mathrm{~m}$ under the same water level in Wenjiazhen during the middle water period from 1956 to 1990, and the riverbed change is the main reason for the basically stable Lijiadu water level in this period; the water level correlation between the two stations has little change from 1990 to 2010. During the dry season from 2010 to 2018, the water level of Lijiadu decreased by about $1.0 \mathrm{~m}$ under the same water level in Wenjiazhen, accounting for about $30 \%$ of the decline value of Lijiadu water level in the same period, while the impact value of the downstream water level decline accounted for about $70 \%$, which is the main reason for the water level decline of Lijiadu.

The water level correlation between Wenjiazhen and Sanyang is scattered due to the supporting effect of Poyang Lake. From the change trend, the correlation between the two had little change before 1970. During the dry season from 1970 to 1990 , the drawdown value of Wenjiazhen station was about $0.5 \mathrm{~m}$ under the same water level at Sanyang station, accounting for $50 \%$ of the water level decline value of Wenjiazhen station. Compared with that in 2018, the drawdown value of Wenjiazhen is about $1.9 \mathrm{~m}$, accounting for about $85 \%$ of the water level drop value of Wenjiazhen. The water level decline of wenjiazhen is mainly affected by the water level drop of Sanyang station downstream.

\section{Conclusions}

The analysis shows that the hydrological situation in the Fuhe River tail has changed greatly in the past 70 years, and the water level under the same discharge has decreased obviously. This phenomenon has little relationship with the change of runoff, which is mainly affected by the changes of riverbed itself and the water level change in the downstream Poyang Lake are. 


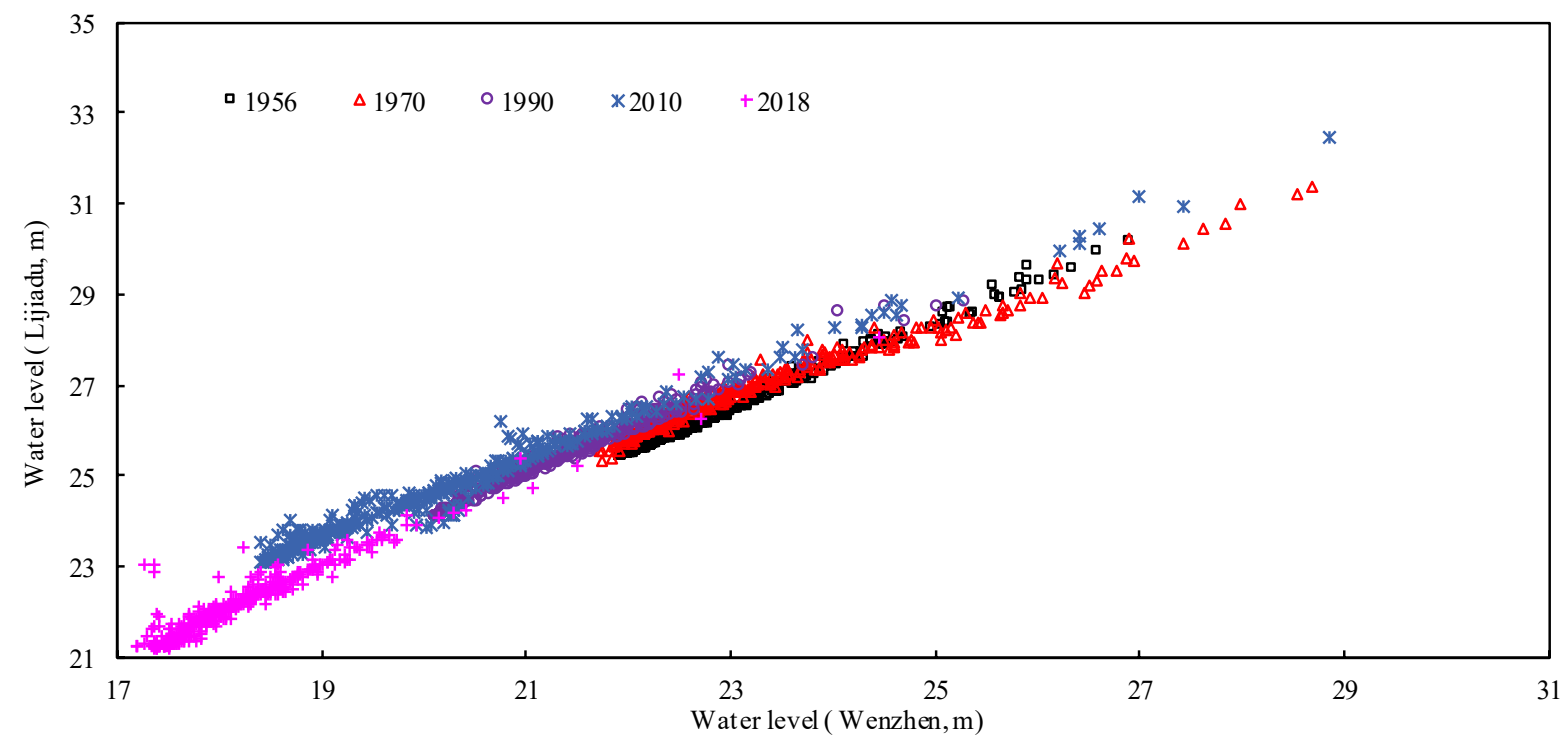

Fig. 5. Water level correlation ship between Lijiadu and Wenzhen.

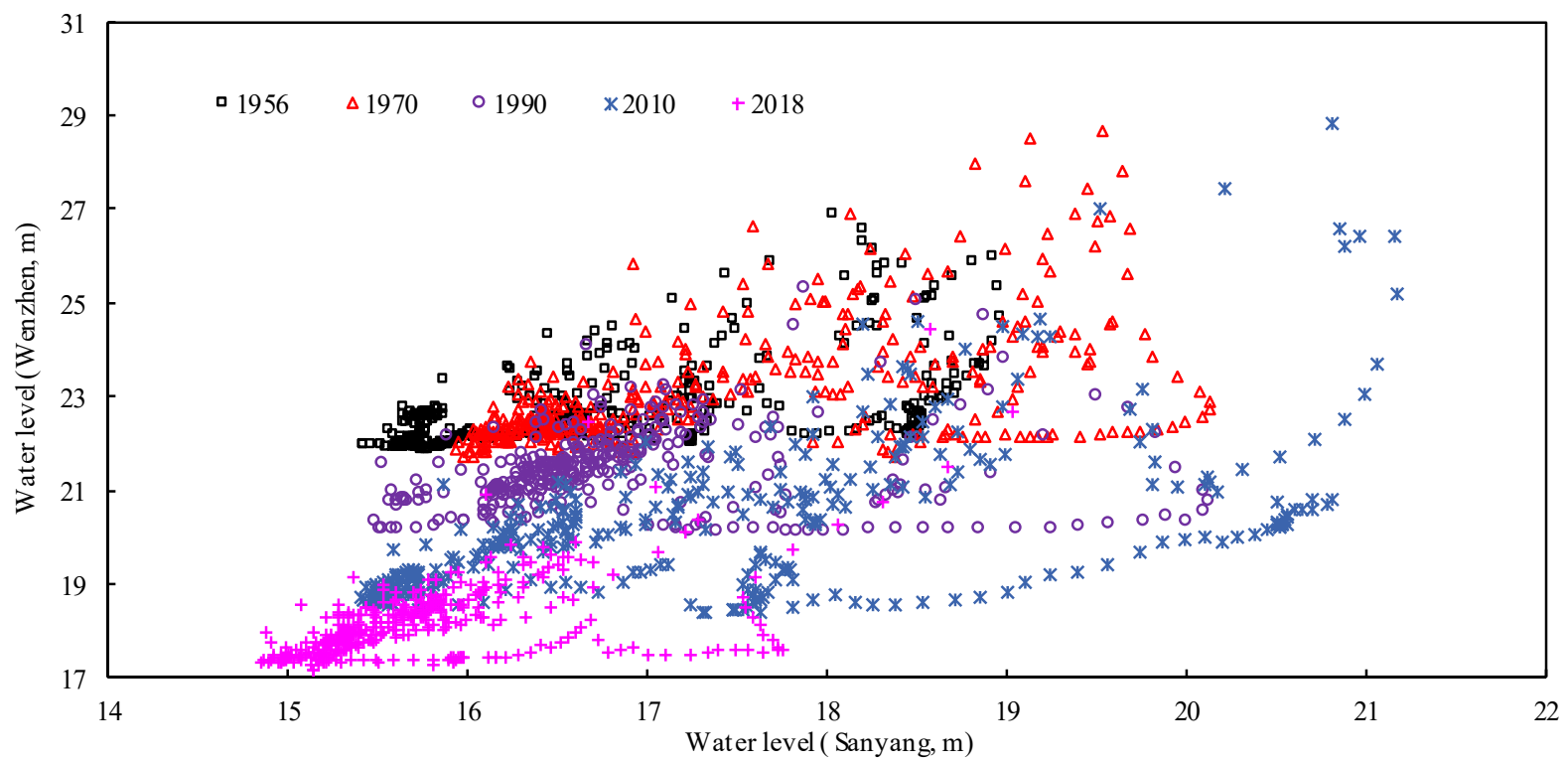

Fig. 6. Water level correlation ship between Wenzhen and Sanyang.

\section{Acknowledgments}

This work was supported by National Key R\&D Program of China 2017YFC0405306.

\section{References}

1. ZHAO Junkai, LI Lixian, LI Jiufa, etc. The Analysis on the Response of the Water Level Change Trend to Human Activities in Poyang Lake. Journal of Jiangxi Normal University (Natural Science), 43(2019)

2. QI Shu-hua, ZHANG Xiu-xiu, JIANG Feng, etc. Research on the causes for hydrological drought trend in Poyang Lake. Journal of Natural Resources, 34(2019)

3. ZHAO Junkai, LI Lixian, LI Jiufa, etc. Response of Stage Variation of the Poyang Lake to Human
Activities. JOURNAL OF CHINA HYDROLOGY, 40(2020)

4. LIU Qijun, CHEN Long. Analysis of water regimen variation trend and cause for Ganjiang River tail channel. JIANGXI HYDRAULIC SCIENCE \& TECHNOLOGY, 43(2017)

5. Chen Jieren, Liu Hanxin, Lv Ting. Analysis of low water level variation and cause for Gangjiang trail channel. Water resource and power, 34(2016) 